\title{
Identyfikacja i prognozowanie szeregów czasowych na przykładzie modeli Boxa-Jenkinsa
}

\author{
Nataliia Kashpruk (D)
}

AGH Akademia Górniczo-Hutnicza, Wydział Elektrotechniki, Automatyki, Informatyki i Inżynierii Biomedycznej, Kraków

Streszczenie: Szeregi czasowe wykorzystywane są do analiz i prognozowania. Na podstawie danych historycznych należy określić, co stanie się ze wskaźnikami w najbliższej przyszłości. Uzyskanie dokładnej prognozy zależy od doboru parametrów modelu. Klasyczne podejście wymaga dużych nakładów pracy i jest czasochłonne. W celu doboru najlepszego modelu często są używane kryteria informacyjne. Celem artykułu było pokazanie, jak należy stosować pakiet autoarima.

Słowa kluczowe: identyfikacja, prognozowanie, szeregi czasowe, ARIMA, autoarima

\section{TIME SERIES IDENTIFICATION AND FORECASTING ON THE EXAMPLE OF BOX-JENKINS MODELS}

\begin{abstract}
Time series are used for analysis and forecasting. Based on historical data, determine what will happen to the indicators in the near future. Obtaining an accurate forecast depends on the selection of model parameters. The classic approach requires a lot of work and is time-consuming. In order to select the best model, information criteria are often used. The aim of this article was to show how to use the autoarima package.
\end{abstract}

Keywords: identification, forecasting, time series, ARIMA, autoarima

https://doi.org/10.7494/978-83-66727-47-2_5 


\section{Wprowadzenie}

Mamy do czynienia ze zbiorami danych uporządkowanych czasowo (rynki finansowe, procesy makroekonomiczne, procesy technologiczne). Modele szeregów czasowych zalicza się do statystycznych metod modelowania. Metody statystyczne w badaniach danych empirycznych rozwinęły się najpierw w dziedzinie ekonomii i finansów. Stosowane są również w planowaniu i sprzedaży. Ważnym obszarem jest również teoria sterowania. Badania statystyczne opierają się na analizie szeregów obserwacji procesów rzeczywistych.

Do modeli statystycznych szeregów czasowych zalicza się m.in. modele autoregresji AR (Auto Regressive), modele ze średnią ruchomą MA (Moving Average), modele ARMA (Auto Regressive Moving Average) stanowiące kombinację obydwu wymienionych typów, zintegrowane modele ARMA, czyli modele ARIMA (AutoRegressive Integrated Moving Average) i ARIMAX (AutoRegressive Integrated Moving Average with exogenous inputs) (Box i Jenkins 1970, Brockwell i Davis 1996, Welfe 2019).

W latach 60. i 70. XX wieku wielu autorów, wśród nich G.E.P. Box i G.M. Jenkins, zajmowało się zagadnieniami statystycznych aspektów układów dynamicznych, sterowania adaptacyjnego, filtracji, prognozy, modeli dyskretnych szeregów czasowych i ich własności. Usystematyzowanie tej tematyki znalazło się w słynnej monografii Boxa i Jenkinsa pt. Time Series Analysis: Forecasting and Control (1970) z późniejszymi wydaniami. Box i Jenkins ze współautorami (Box i in. 2015) opracowali podejście do modelowania szeregów czasowych w czasie rzeczywistym oraz kompletne podejście do budowania modelu, szacowania, prognozowania i kontroli.

Wśród modeli opracowanych przez Boxa i Jenkinsa szerokie zastosowanie znalazły modele autoregresji skończonego rzędu $p$, oznaczane jako $\operatorname{AR}(p)$. Zakłada się w nich, że badany proces stochastyczny jest stacjonarny, a prognozowanie jego przyszłych wartości jest kombinacją liniową przeszłych i obecnych zaobserwowanych wartości procesu. Model autoregresji jest procesem losowym o nieskorelowanych wyrazach i skończonej wariancji.

Także dla stacjonarnych procesów stochastycznych opracowano model średniej ruchomej, MA $(q)$. Prognoza procesu jest sumą ważoną skończonej liczby wyrazów nieskorelowanego procesu losowego. Jest to rozwinięcie sformułowanej przez Yule'a (1926) koncepcji filtru liniowego o skończonej liczbie wyrazów. Kombinacją obydwu modeli jest model $\operatorname{ARMA}(p, q)$, który jest często stosowany w praktyce do prognozowania różnych zjawisk i procesów.

Na szczególną uwagę zasługuje model ARIMA, czyli zintegrowany model ARMA, przeznaczony do modelowania niestacjonarnych procesów stochastycznych. Według niektórych badaczy, mimo swych zalet i elastyczności, model ARIMA jest techniką złożoną; nie jest łatwy w użyciu i wymaga dużego doświadczenia (Bails i Peppers 1982). 
W artykule Ceylan (2020) opracowano zintegrowane modele autoregresyjne ze średniej ruchomej (ARIMA) do przewidywania trendu występowania COVID-19 w krajach najbardziej dotkniętych epidemią. Badania z zastosowaniem modeli ARIMA opisano w następujących pracach naukowych: Benvenuto i in. (2020) oraz Tandon i in. (2020). W niniejszej pracy przedstawiono model ARIMA oraz metody służące do jego strojenia.

\section{Model ARIMA}

Model ARIMA służy do analizy statystycznej i wykorzystuje dane szeregów czasowych do przewidywania przyszłych tendencji. Ten model jest formą analizy regresji, która mierzy siłę jednej zmiennej zależnej w stosunku do innych zmiennych. Ponadto jest szeroko stosowany do prognozowania przyszłych wartości danych, jako że umożliwia badanie różnic między wartościami w ciągach zamiast wartości oryginalnych (Ljung 1998). Modele ARIMA mogą być szczególnie skuteczne w przypadkach, w których dane wykazują niestacjonarność (Stellwagen i Tashman 2013).

Model ARIMA jest klasycznym modelem statystycznym do prognozowania i analizy szeregów czasowych i jest złożony z następujących elementów (Brownlee 2017):

- autoregresja (AR) - model pokazuje regresję zmiennej do poprzednich wartości;

- całkowanie (I) - dane zostają zastąpione różnicą między ich wartościami a poprzednimi znaczeniami (i ten proces różnicowania mógł zostać wykonany więcej niż raz);

- średnia ruchoma (MA) - model wykorzystuje zależność między obserwacją a błędami reszt z modelu średniej ruchomej zastosowanej do obserwacji opóźnionych.

Każdy z tych komponentów jest wyraźnie określony w modelu jako parametr i ma na celu jak najlepsze dopasowanie modelu do danych.

W przypadku modeli ARIMA domyślną notacją będzie ARIMA z parametrami $p, d$ i $q$, gdzie parametry są zastępowane wartościami całkowitymi, aby wskazać rząd modelu.

Parametry modelu ARIMA są zdefiniowane w następujący sposób (Söderström i Stoica 1997):

$p$ - liczba opóźnień obserwacji w modelu (parametr autoregresyjny),

$d$ - stopień różnicy (rząd różnicowania),

$q$ - zakres średniej ruchomej (parametr średniej ruchomej).

Model ARIMA $(p, d, q)$ opisany jest wzorem:

$$
\Delta^{d} y_{t}=c+\sum_{i=1}^{p} \varnothing_{i} \Delta^{d} y_{t-1}+\sum_{i=1}^{q} \theta_{j} \varepsilon_{t}
$$


Wyróżniamy modele ARIMA z uwzględnieniem sezonowości. Niesezonowe modele ARIMA są zazwyczaj oznaczane jako ARIMA $(p, d, q)$, gdzie parametry $p, d$ i $q$ są liczbami naturalnymi. Sezonowe modele ARIMA są zwykle oznaczane jako ARIMA $(p, d, q)(\mathrm{P}, \mathrm{D}, \mathrm{Q})[m]$, gdzie $[m]$ odnosi się do liczby okresów w każdym sezonie, a wielkie litery P, D, Q oznaczają składniki autoregresji, różnicowania i średniej ruchomej dla sezonowej części modelu ARIMA (Pulagam 2020).

Model ARIMA można zbudować na wiele sposobów, aby pełnił funkcję modelu ARMA bądź prostych modeli AR, I lub MA. Modele ARIMA są wykorzystywane przy opisie szumu w zakłóceniach. Gdy dwa z trzech terminów są zerami, model można stosować na podstawie niezerowego parametru, pomijając „AR”, „I” lub „MA” z akronimu oznaczającego model. Na przykład ARIMA(1,0,0) to jest $\operatorname{AR}(1), \operatorname{ARIMA}(0,1,0)$ to jest I(1), a ARIMA(0,0,1) to jest MA(1) (Taylor G Smith 2017-2021b).

\section{Klasyczny algorytm konstrukcji modeli ARIMA}

Box i Jenkins (1983) zaprezentowali etapy modelowania szeregów czasowych:

1. Testowanie stacjonarności i sezonowości.

2. Znajdowanie obiecujących propozycji modeli.

3. Dopasowywanie modeli i zawężanie ich wyboru za pomocą kryteriów informacyjnych Akaikiego i Bayesa (AIC i BIC).

4. Wykonywanie testów diagnostycznych modeli.

5. Tworzenie prognoz.

Analiza Boxa-Jenkinsa odnosi się do systematycznej metody identyfikacji, dopasowywania, sprawdzania i wykorzystywania zintegrowanych modeli szeregów czasowych z autoregresją i średnią ruchomą.

Skuteczną procedurę Boxa-Jenkinsa budowania empirycznych modeli ciągów czasowych można zrealizować w trzech etapach:

1. Specyfikacja lub identyfikacja modelu (z wykorzystaniem wykresów danych, autokorelacji, częściowych autokorelacji i innych informacji wybiera się klasę prostych modeli ARIMA, co sprowadza się do oszacowania odpowiednich wartości parametrów $p, d$ i $q$ ).

2. Estymacja modeli.

3. Diagnostyka lub testowanie modeli (dopasowany model jest sprawdzany pod kątem niedoskonałości z uwzględnieniem autokorelacji reszt modelu).

Powyższe kroki są stosowane iteracyjnie, dopóki krok trzeci nie przyniesie żadnej poprawy w modelu (Hintze 2007). Metodą bazującą na tym podejściu jest pakiet autoarima. 


\section{Pakiet autoarima w Pythonie}

W klasycznym modelu ARIMA musimy obliczyć wartości $p, d$ i $q$. Używamy technik statystycznych do generowania tych wartości, obliczając różnicę w celu wyeliminowania niestacjonarności oraz wykreślając wykresy funkcji autokorelacji i częściowej autokorelacji (ACF i PACF). W autoarima algorytm wygeneruje optymalne wartości $p, d$ i $q$, tj. optymalne parametry modelu, aby zapewnić dokładniejsze prognozowanie (Maklin 2019).

Pmdarima składa się z kilku różnych bibliotek statystycznych i uczenia maszynowego i działa przez uogólnienie wszystkich modeli ARIMA w jedną klasę. Do modeli statystycznych (ARMA, ARIMA i SARIMAX) stosowano bibliotekę statsmodels (Taylor G Smith 2017-2021a).

Funkcja autoarima testuje różne zestawy $p$ i $q$ (również $P$ i $Q$ dla modeli sezonowych), wybierając model, który minimalizuje AIC (lub inne kryteria informacyjne). Aby wybrać warunki różnicujące, autoarima używa testu stacjonarności (takiego jak rozszerzony test Dickeya-Fullera) i sezonowości (takiego jak test Canovy-Hansena) dla modeli sezonowych (RDocumentation 2021).

W statystyce i ekonometrii rozszerzony test Dickeya-Fullera (ADF) sprawdza hipotezę zerową pierwiastka jednostkowego w próbie szeregów czasowych. Hipoteza alternatywna jest różna w zależności od używanej wersji testu, ale zwykle jest to stacjonarność lub trendostacjonarność. Jest to rozszerzona wersja testu Dickeya-Fullera dla większego i bardziej skomplikowanego zestawu modeli szeregów czasowych.

Autoarima dobiera najlepszy model na podstawie kryteriów informacyjnych z najmniejszą wartością i zwraca model ARIMA z odpowiednimi parametrami. W artykule brane są pod uwagę kryteria informacyjne AIC (Taylor G Smith 2017-2021b).

Kryterium informacyjne Akaikego (AIC - Akaike Information Criterion) jest estymatorem względnej jakości modeli statystycznych dla danego zbioru danych. Biorąc pod uwagę zbiór danych, AIC szacuje jakość każdego modelu w stosunku do każdego z pozostałych modeli. Wartość AIC pozwala oszacować, jak dobrze model pasuje do danych i ocenić złożoność modelu, więc modele, które mają lepsze dopasowanie przy użyciu mniejszej liczby funkcji, otrzymają lepszy wynik AIC niż podobne modele, które wykorzystują więcej funkcji. AIC przedstawia następujący wzór (Akaike 1973):

$$
A I C=\frac{2 k}{n}+\ln \left(\frac{1}{n} \sum_{i=1}^{n}\left(x_{i}-\hat{x}_{i}\right)^{2}\right)
$$

gdzie:

$x_{i}$ - rzeczywista wartość ciągu,

$\hat{x}_{i}-$ wyjściowa wartość modelu,

$n$ - długość ciągu czasowego,

$k$ - liczba parametrów. 
Pakiet pmdarima w Pythonie pozwala szybko przeprowadzić wyszukiwanie w siatce, a nawet tworzy obiekt modelowy, który można dopasować do danych treningowych. Warto zwrócić uwagę, że ze względu na problemy ze stacjonarnością autoarima może nie znaleźć odpowiedniego modelu. W takim przypadku nastąpi zgłoszenie błędu ValueError, sugerujące podjęcie środków indukujących stacjonarność przed ponownym dopasowaniem lub wybranie nowego zakresu wartości zamówienia. Wybór niestopniowy (tj. zasadniczo przeszukiwanie siatki) może być powolny, szczególnie w przypadku danych sezonowych. Algorytm krokowy został opisany przez Hyndmana i Khandakara (2008) oraz na stronie alkaline-ml (Taylor G Smith 2017-2021b).

\section{Przykład stosowania autoarima w Pythonie}

W obliczeniach wykorzystano zestaw danych dotyczących miesięcznej sprzedaży szampana od 1964 do 1972 roku (rys. 1).

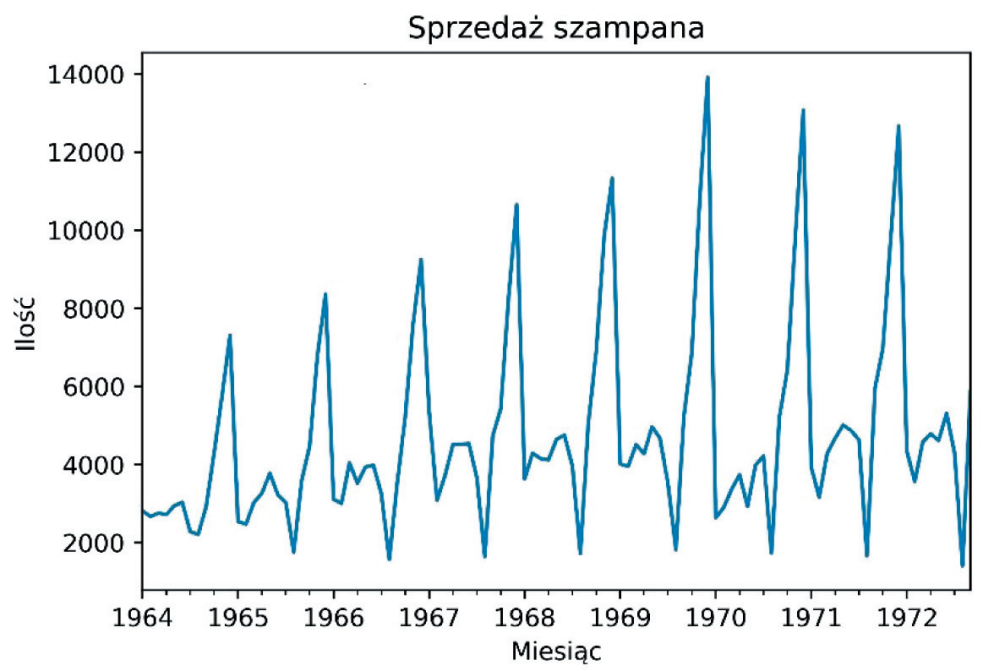

Rys. 1. Sprzedaż szampana w latach 1964-1972

Źródło: opracowanie własne na podstawie Pulagam (2020)

Z wykresu widać, że obserwowane dane mają sezonowy charakter. Każdego roku, od 1964 do 1972 roku, w okresie karnawału następuje gwałtowny wzrost sprzedaży. Stacjonarność jest ważnym pojęciem w odniesieniu do szeregów czasowych i wszelkie dane szeregów czasowych powinny zostać poddane testowi stacjonarności przed przystąpieniem do konstruowania modelu. W celu sprawdzenia danych pod kątem stacjo- 
narności należy wykonać test ADF w pakiecie pmdarima w Pythonie. Wynik testu (0.01, False) wskazuje, że dane są niestacjonarne (Pulagam 2020).

Kolejnym krokiem jest podział danych na treningowe i testowe, aby zbudować model na uczącym zestawie danych i prognozować przy użyciu testowego zestawu danych.

Następnym etapem jest wykorzystanie wytrenowanego modelu, który został zbudowany we wcześniejszym kroku, do prognozowania sprzedaży na danych testowych.

$\mathrm{W}$ autoarima wartości $p, d, q$ reprezentują składniki niesezonowe, a $\mathrm{P}, \mathrm{D}, \mathrm{Q}$ reprezentują składniki sezonowe. Jakość predykcji zależy od doboru optymalnych wartości $p, d$ i $q$ (tab. 1) z różnymi kombinacjami oraz z uwzględnieniem niższych parametrów AIC (Pulagam 2020).

Tabela 1

Dobór parametrów modelu ARIMA z najmniejszym AIC

\begin{tabular}{|ll|}
\hline ARIMA $(0,1,0)(0,1,0)[12]$ & $:$ AIC $=1203.853$, \\
\hline ARIMA $(1,1,0)(1,1,0)[12]$ & $:$ AIC $=1192.025$, \\
\hline ARIMA $(0,1,1)(0,1,1)[12]$ & $:$ AIC $=1176.246$, \\
\hline ARIMA $(0,1,1)(0,1,0)[12]$ & $:$ AIC $=1174.731$, \\
\hline ARIMA $(0,1,1)(1,1,0)[12]$ & $:$ AIC $=1176.034$, \\
\hline ARIMA $(0,1,1)(1,1,1)[12]$ & $:$ AIC $=1176.700$, \\
\hline ARIMA $(1,1,1)(0,1,0)[12]$ & $:$ AIC $=1175.054$, \\
\hline ARIMA $(0,1,2)(0,1,0)[12]$ & $:$ AIC $=1174.769$, \\
\hline ARIMA $(1,1,0)(0,1,0)[12]$ & $:$ AIC $=1194.721$, \\
\hline ARIMA $(1,1,2)(0,1,0)[12]$ & $:$ AIC $=1174.564$, \\
\hline ARIMA $(1,1,2)(1,1,0)[12]$ & $:$ AIC $=i n f$, \\
\hline ARIMA $(1,1,2)(0,1,1)[12]$ & $:$ AIC $=i n f$, \\
\hline ARIMA $(1,1,2)(1,1,1)[12]$ & $:$ AIC $=1176.738$, \\
\hline ARIMA $(2,1,2)(0,1,0)[12]$ & $:$ AIC $=1176.127$, \\
\hline ARIMA $(1,1,3)(0,1,0)[12]$ & $:$ AIC $=1176.124$, \\
\hline ARIMA $(0,1,3)(0,1,0)[12]$ & $:$ AIC $=1176.458$, \\
\hline ARIMA $(2,1,1)(0,1,0)[12]$ & $:$ AIC $=1176.656$, \\
\hline ARIMA $(2,1,3)(0,1,0)[12]$ & $:$ AIC $=1180.583$, \\
\hline ARIMA $(1,1,2)(0,1,0)[12]$ intercept $:$ AIC $=$ inf., \\
\hline Najlepszy model: ARIMA(1,1,2)(0,1,0)[12] \\
\hline
\end{tabular}

W tabeli 2 znajduje się podsumowanie wybranego modelu $\operatorname{ARIMA}(1,1,2)(0,1,0)$ [12] w Pythonie.

Na rysunku 2 przedstawiono prognozę sprzedaży szampana na podstawie danych testowych w Pythonie. 
Tabela 2

Podsumowanie najlepszego modelu

\begin{tabular}{|l|l|}
\hline Zmienna & $\mathrm{y}$ \\
\hline Model & ARIMAX $(1,1,2)(0,1,0)[12]$ \\
\hline Liczba obserwacji & 85 \\
\hline Prawdopodobieństwo & $-583,282$ \\
\hline AIC & 1174,564 \\
\hline BIC & 1183,670 \\
\hline HQIC & 1178,189 \\
\hline
\end{tabular}

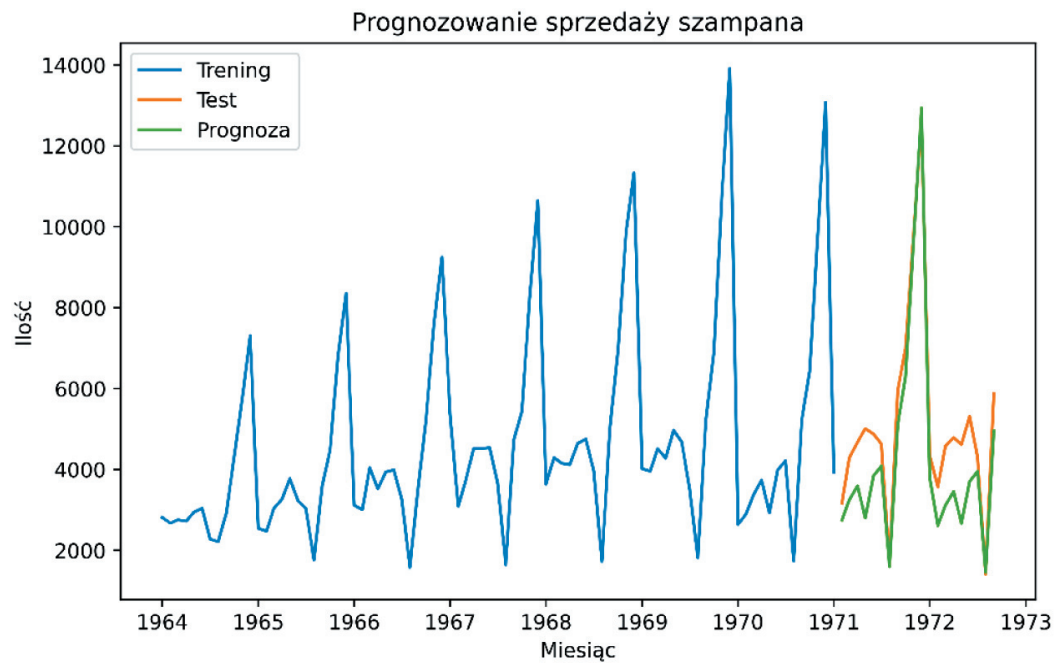

Rys. 2. Prognoza sprzedaży szampana w pmdarima

Źródło: opracowanie własne na podstawie Pulagam (2020)

Analiza sprzedaży i zapasów towarów umożliwi efektywne zarządzanie całym łańcuchem dostaw. Dlatego ważnym elementem w biznesie jest analiza i predykcja sprzedaży na podstawie danych i faktów. Pozwala to na czerpanie korzyści ze sprzedaży. Do prognozowania sprzedaży na danych testowych stosujemy model treningowy. Na rysunku 2 przedstawiono wygenerowaną prognozę porównaną z danymi rzeczywistymi. Prognoza popytu jest dobrze dopasowana do danych testowych.

\section{Podsumowanie}

Problem prognozowania rozwiązuje się najczęściej przy zastosowaniu metod predykcji opartych na szeregach czasowych z jedną zmienną, takich jak AR, ARMA czy ARIMA. Najważniejszym krokiem w wyborze odpowiedniego modelu jest określe- 
nie optymalnych parametrów. W modelach statystycznych wartość prognozy jest wartością wyjściową modelu, czyli wartością funkcji wyznaczonej na podstawie aktualnych obserwacji.

W artykule przedstawiono, jak korzystać z funkcjonalności modelu autoarima w celu doboru najlepszego modelu do predykcji.

W klasycznym modelu ARIMA lub SARIMA należy wykonać różnicowanie i wykreślić wykresy ACF i PACF, co jest czasochłonne. Pokazano przykład prognozy dla danych sprzedaży szampana z zastosowaniem autoarima $\mathrm{z}$ pakietu pmdarima $\mathrm{w}$ Pythonie.

Zaletami autoarima są:

- oszczędność czasu na zrozumienie statystyki oraz dobór najlepszego modelu,

- szybkość obliczenia,

- wyeliminowanie ryzyka nieprawidłowej interpretacji wyników przez człowieka.

Do wad można zaliczyć zależność od kryteriów informacyjnych, np. AIC wynosi logarytmiczną wartość prawdopodobieństwa i nigdy nie dowiemy się, który model był najbardziej zbliżony do najlepszego.

Kierunkiem dalszych prac jest badanie wpływu kryteriów informacyjnych w modelach szeregów czasowych na predykcje rozwoju pandemii COVID-19.

\section{Podziękowania}

Autorka dziękuje Recenzentowi za celne uwagi, które pomogły ulepszyć artykuł.

\section{Literatura}

Akaike H., 1973, Information theory and an extension of the maximum likelihood principle, [w:] Petrov B.N., Csaki F. (ed.), 2nd International Symposium on Information Theory, Tsahkadsor, Armenia, USSR, September 2-8, 1971, Akadémiai Kiadó, Budapest, s. 267-281.

Bails D.G., Peppers L.C., 1982, Business fluctuations: Forecasting techniques and applications, Prentice-Hall International, Hemel Hempstead.

Benvenuto D., Giovanetti M., Vassallo L., Angeletti S., Ciccozzi M., 2020, Application of the ARIMA model on the COVID-2019 epidemic dataset, Data in Brief, vol. 29, 105340. https://doi.org/10.1016/j.dib.2020.105340.

Box G., Jenkins G., 1970, Time Series Analysis: Forecasting and Control, Holden-Day, San Francisco.

Box G., Jenkins G., 1983, Analiza szeregów czasowych: prognozowanie i sterowanie, Państwowe Wydawnictwo Naukowe, Warszawa.

Box G., Jenkins G., Reinsel G., Ljung G., 2015, Time Series Analysis: Forecasting and Control, $5^{\text {th }}$ ed., John Wiley and Sons, Hoboken, New Jersey. 
Brockwell P.J., Davis R.A., 1996, Introduction to Time Series and Forecasting, Springer-Verlag, New York.

Brownlee J., 2017, How to Create an ARIMA Model for Time Series Forecasting in Python, Machine Learning Mastery. https://machinelearningmastery.com/arimafor-time-series-forecasting-with-python/ [dostęp: 28.06.2021].

Ceylan Z., 2020, Estimation of COVID-19 prevalence in Italy, Spain, and France, Science of The Total Environment, vol. 729, 138817. https://doi.org/10.1016/j.scitotenv.2020.138817. Hintze J.L., 2007, The Box-Jenkins Method, [w:] Hintze J.L., User's Gide IV: Multivariate Analysis, Clustering, Meta-Analysis, Forecasting / Time Series, Operations Research, Mass Appraisal, NCSS, Kaysville, Utah, s. 470-1-470.14.

Hyndman R.J., Khandakar Y., 2008, Automatic Time Series Forecasting: The Forecast Package for $R$, Journal of Statistical Software, vol. 27, s. 1-22. https://doi.org/ 10.18637/jss.v027.i03.

Ljung L., 1998, System Identification: Theory for the User, $2^{\text {nd }}$ ed., Pearson Education. Maklin C., 2019, ARIMA Model Python Example - Time Series Forecasting, https:// towardsdatascience.com/machine-learning-part-19-time-series-and-autoregressiveintegrated-moving-average-model-arima-c1005347b0d7 [dostęp: 24.06.2021].

Pulagam S., 2020, Time Series forecasting using Auto ARIMA in Python, Towards Data Science, https://towardsdatascience.com/time-series-forecasting-using-auto-arima-inpython-bb83e49210cd [dostęp: 25.06.2021].

RDocumentation, 2021, Forecast, https://rdocumentation.org/packages/forecast/versions/8.15 [dostęp: 13.09.2021].

Söderström T., Stoica P., 1997, Identyfikacja systemów, Wydawnictwo Naukowe PWN, Warszawa.

Stellwagen E., Tashman L., 2013, ARIMA: The Models of Box and Jenkins, Foresight: The International Journal of Applied Forecasting, iss. 30, s. 28-33.

Tandon H., Ranjan P., Chakraborty T., Suhag V., 2020, Coronavirus (COVID-19): ARIMA based time-series analysis to forecast near future, https://arxiv.org/abs/2004.07859 [dostęp: 25.06.2021].

Taylor G Smith, 2017-2021a, pmdarima: ARIMA estimators for Python, http://www. alkaline-ml.com/pmdarima [dostęp: 13.09.2021].

Taylor G Smith, 2017-2021b, User Guide, http://www.alkaline-ml.com/pmdarima/user_ guide.html\#user-guide [dostęp: 13.09.2021].

Welfe A., 2019, Ekonometria: metody i ich zastosowania, Państwowe Wydawnictwo Ekonomiczne, Warszawa.

Yule G.U., 1926, Why Do We Sometimes Get Nonsense-Correlations between Time Series? A Study in Sampling and the Nature of Time Series, Journal of Royal Statistical Society, vol. 89, no. 1, s. 1-64. https://doi.org/10.2307/2341482. 